\title{
CARACTERIZAÇÃO DA BACIA HIDROGRÁFICA DO CÓRREGO JACOBINA, MUNICÍPIO DE CÁCERES-MT
}

\author{
Beatriz Ferraz Bühler ${ }^{1}$, Célia Alves de Souza ${ }^{2}$, Willian Cosme da Silveira de Paula ${ }^{3}$ \\ ${ }^{1}$ Mestranda em Ciências Ambientais - Universidade do Estado de Mato Grosso, \\ Cáceres-MT, Brasil; bfbuhler@gmail.com; \\ ${ }^{2}$ Professora Adjunto do Depto de Geografia - Universidade do Estado de Mato \\ Grosso, Cáceres-MT, Brasil; \\ ${ }^{3}$ Graduando em Geografia - Universidade do Estado de Mato Grosso, Cáceres-MT, \\ Brasil;
}

Recebido em: 08/04/2016 - Aprovado em: 30/05/2016 - Publicado em: 20/06/2016 DOI: 10.18677/Enciclopedia_Biosfera_2016_139

\begin{abstract}
RESUMO
As bacias hidrográficas são unidades de recepção de águas e sedimentos que interagem com os elementos ambientais que a compõem. $O$ estudo das bacias permite contribuir com a gestão ambiental. Esta pesquisa objetivou caracterizar a bacia hidrográfica do córrego Jacobina, no município de Cáceres-MT quanto à geologia, geomorfologia, clima, solo e vegetação. Para tanto, o canal foi compartimentado em alto, médio e baixo curso. O levantamento dos tipos de solo, vegetação e geologia foi realizado com a interpretação de mapas temáticos elaborados a partir do projeto RADAMBRASIL através de imagens de satélite LANDSAT TM 5 e TM 8 em escala 1:210.000. Foram realizadas visitas in loco para observação direta do local e comparação dos resultados obtidos da interpretação dos mapas. No alto curso predomina a Savana Arborizada, solos do tipo Argissolo Vermelho Eutrófico e rochas da Formação Moendas. No médio curso, a vegetação predominante é a pastagem com solo do tipo Argissolo Vermelho Eutrófico e rochas da Formação Araras. No baixo curso, a vegetação é do tipo savânica arborizada com um pequeno segmento de floresta estacional no trecho em que as águas do córrego encontram as águas do rio Paraguai e predominam solos do tipo Argissolo Vermelho-Amarelo Distrófico. O clima da bacia é tropical e diferencia-se nos planaltos e chapadas do alto e médio cursos e subúmido nas depressões do baixo curso característico dos pantanais de Mato Grosso. O canal fluvial possui padrão meandrante encaixado em vale, desaguando na margem esquerda do rio Paraguai à altitude aproximada de $110 \mathrm{~m}$.
\end{abstract}

PALAVRAS-CHAVE: Elementos ambientais, geomorfologia fluvial, mapas temáticos.

\section{ENVIRONMENTAL CHARACTERISTICS OF THE RIVER BASIN OF JACOBINA STREAM , MUNICIPALITY OF CACERES -MT}

\begin{abstract}
Watersheds are unities of water and sediments reception that interact the environmental elements which compose it. The study of the basins provides contribution to the environmental management. This research aimed to characterize
\end{abstract}


the watershed of the Jacobina's stream, at the municipality of Cáceres, in the State of Mato Grosso, covering geology, geomorphology, climate, soil and vegetation type. Therefore, the channel of the stream was compartmentalized in high, middle and low course. The survey of the soil type, vegetation and geology was conducted with the interpretation of thematic maps elaborated from the RADAMBRASIL project using LANDSAT TM 5 and TM 8 satellite images in scale of 1:210.000. Research in locus was also conducted in order to compare the direct local observation and compare it with the obtained results of the maps interpretation. At the high course prevails the Wooded Savanna, soil type Argisol Red Eutrophic and rocks of the Moenda's Formation. At the middle course, the vegetation most common was the pasture with the soil type Argisol Red Eutrophic and rocks of the Arara's Formation. At the low course, the vegetation type is Wooded Savanna with a small segment of seasons forest on the way that the waters of the stream find the waters of the Paraguay river and prevails Argisol Red-Yellow Dystrophic as soil type. The climate of the basin is tropical and differs at the plains and plateaus at high and middle course and subhumid at the valleys of the low course, characteristic of the Pantanal of Mato Grosso. The fluvial channel has meandering pattern embedded in valley, flowing into the left shore of the Paraguai river to the altitude next to $110 \mathrm{~m}$.

KEYWORDS: Environmental elements, fluvial geomorphology, thematic maps.

\section{INTRODUÇÃO}

Uma bacia hidrográfica constitui-se de um conjunto de terras drenadas por um rio principal e seus afluentes, em que se verifica a concentração das águas das chuvas nas depressões longitudinais, escoando dos pontos mais altos para os mais baixos (GUERRA \& GUERRA, 2008). Na bacia, ocorrem interações entre vários fatores, tais como clima, geologia, vegetação, geomorfologia e solo que ao se relacionarem, fornecem características e explicam sua estrutura e comportamento (SOUZA \& CUNHA, 2012).

Os estudos relativos à geomorfologia explicam as formas de relevo, sua formação e tamanho, bem como sua relação com os diversos componentes da natureza (ROSS, 2011), enquanto a constituição e a estrutura da Terra são explicadas pela geologia, que define aspectos como as diferentes forças que atuam sobre as rochas e também sua disposição, modificando as formas de relevo e a composição química dos elementos iniciais (GUERRA \& GUERRA, 2008).

A litologia e a estrutura são duas propriedades fundamentais das rochas. Enquanto a primeira refere-se à composição mineral, tamanho e dureza dos grãos, a segunda refere-se ao grau e tipo de cimentação das camadas das rochas, grau ou tipo de fissuração vertical e acabamento horizontal, além da deformação interna das rochas (TORRES et al., 2012).

Não somente a geologia e a geomorfologia, mas também a vegetação e o solo constituem importantes fatores na manutenção dos ecossistemas e desempenham papel fundamental na composição dos elementos de uma bacia hidrográfica. Ademais, a interface entre solo-vegetação na atmosfera exerce forte influência no ciclo hidrológico (TUCCI \& MENDES, 2006).

As formações vegetais, especialmente as matas ciliares, são importantes para a manutenção dos ecossistemas haja vista que dificultam o escoamento superficial de sedimentos para dentro dos cursos d'água, promovem sombreamento, minimizam a erosão, facilita a infiltração da água no solo, entre outros fatores (LIMA \& ZAKIA, 2004). 
O elemento clima pode ser definido como o conjunto das condições atmosféricas ao longo do tempo, as médias anuais, a variação da temperatura e precipitação (TEIXEIRA et al. 2009). Desta forma, quando esses elementos se integram podem influenciar no tipo de clima de uma determinada região.

Estas características, em uma bacia, estão relacionadas aos aspectos geológicos, às formas de relevo, aos processos geomorfológicos e às características hidrológicas e climáticas, assim como à biota e à ocupação da Terra (TORRES et al., 2012) e são importante instrumento de pesquisa que permitem conhecer a dinâmica de uma bacia hidrográfica.

No âmbito das pesquisas sobre caracterização ambiental, alguns estudos já foram desenvolvidos no estado de Mato Grosso como RITELA \& SOUZA (2008) ao estudarem o rio Aguapeí, no sentido de levantar informações a respeito da rede de drenagem da bacia e MACEDO et al. (2014) ao realizarem a caracterização geomorfológica na planície do rio Paraguai entre as confluências dos rios Cuiabá e Miranda; A nível nacional, SALAMENE et al. (2011) estratificaram e caracterizaram a área de preservação permanente do rio Guandu/RJ; CONCEIÇÃO et al. (2012) realizaram a caracterização geológica, petrográfica e geoquímica do maciço granítico Glória Sul na faixa de dobramentos sergipana e MARTINS \& COSTA (2014) caracterizaram geográfica e geomorfologicamente o município de ItuiutabaMG.

A bacia hidrográfica do córrego Jacobina está localizada na zona rural do município de Cáceres e abastece a região do entorno para irrigação da agricultura, criação de animais, além de servir como meio de recreação. Percorre várias fazendas da região, desaguando na margem esquerda do rio Paraguai.

Considerando que o levantamento das características ambientais do córrego Jacobina fornecerão dados sobre a sua estrutura e funcionamento, o presente estudo teve como objetivo realizar a caracterização ambiental do córrego Jacobina, município de Cáceres-MT, no que se refere aos aspectos geológicos, geomorfológicos, vegetacionais, climáticos e pedológicos de maneira a relacioná-los com os padrões de drenagem da bacia.

\section{Área de estudo}

\section{MATERIAL E MÉTODOS}

O córrego Jacobina está localizado na região Sudoeste do Estado de Mato Grosso entre as coordenadas geográficas 1691'51,6' ' a 16917'04,4" de latitude Sul e 5731'23.7' a 57\%6'20,1' de longitude Oeste. Su as nascentes localizam-se entre as Serras da Jacobina e da Campina, sendo que a nascente principal está localizada na região rural especificamente na Fazenda Córrego Fundo, à margem esquerda da rodovia BR-070 que liga os municípios de Cáceres à Várzea Grande.

Seus afluentes principais são o ribeirão da Jacobina e córrego Laje, córregos Grande, Salto, Várzea, que percorrem transversalmente ou subsequente à estrutura; desagua no rio Paraguai pela margem esquerda à altitude de $110 \mathrm{~m}$ aproximadamente, conforme Figura 1. 


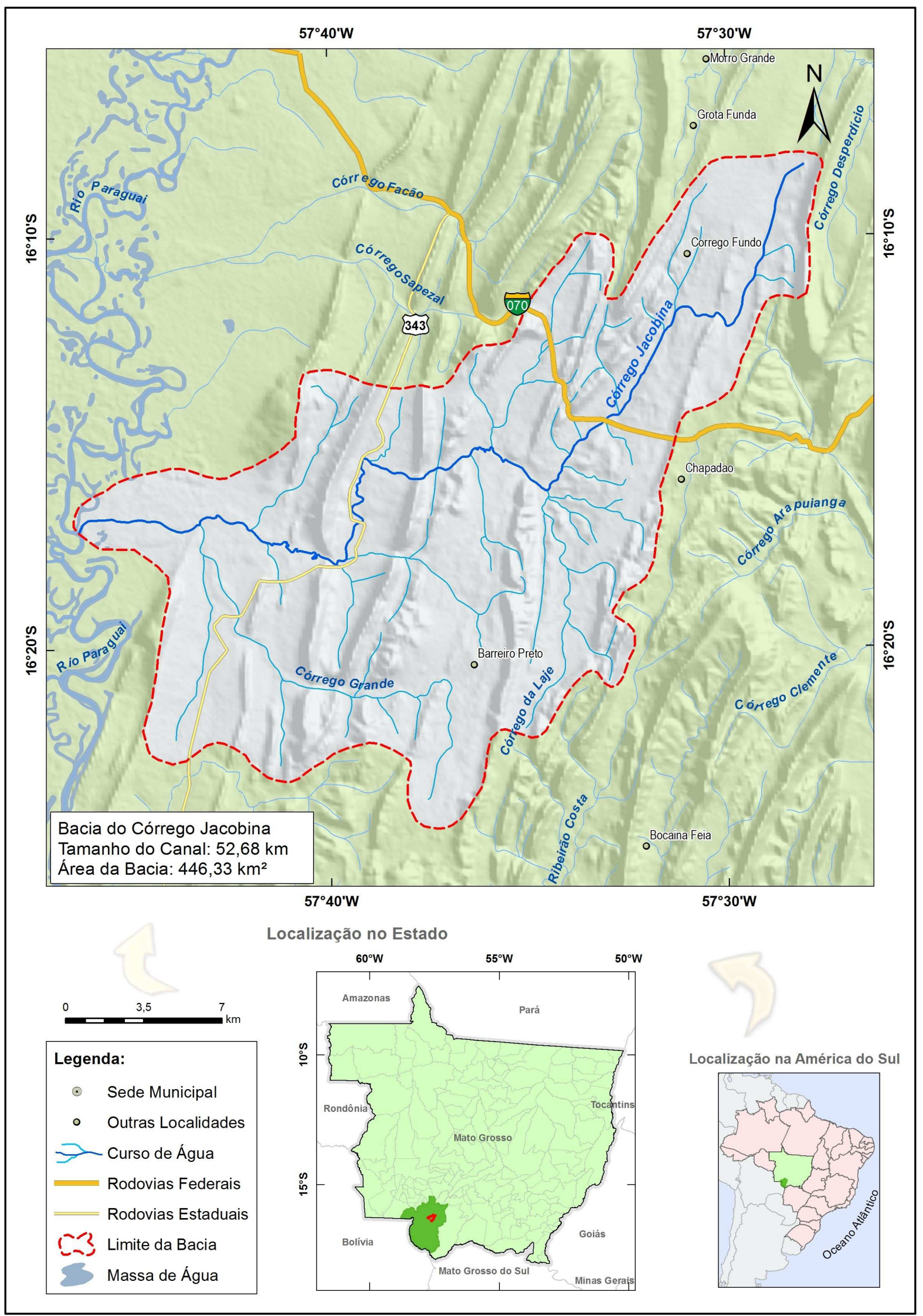

FIGURA 1. Localização da bacia hidrográfica do córrego Jacobina, município de Cáceres-MT.

Elaborado por: Gilmar de Souza Acácio.

ENCICLOPÉDIA BIOSFERA, Centro Científico Conhecer - Goiânia, v.13 n.23; p.1554 


\section{Procedimentos Metodológicos}

\section{Levantamento das características ambientais da bacia}

Para amostrar a área de estudo, foram definidos três compartimentos considerando toda a extensão do córrego nas áreas de nascente, médio curso e a foz, divididos em: Compartimento I: Alto Curso; Compartimento II: Médio Curso e Compartimento III: Baixo Curso, baseados no relevo apresentado pela área.

As informações sobre as condições ambientais da bacia no que se referem ao clima, geologia, geomorfologia, formações vegetais e solo, foram levantadas através de consultas bibliográficas, elaboração de mapas temáticos de vegetação (Figura 2), geologia (Figura 3) e solo (Figura 4) e visitas in loco. Foram analisadas as cartas topográficas de Cáceres e Serra da Campina do Ministério do Exército em escala 1:100.000 que subsidiaram a leitura referente à sua localização no contexto geomorfológico. Os mapas temáticos foram elaborados a partir das informações do Projeto RADAMBRASIL (1982) com auxílio do software ArcGis, versão 10.1 utilizando imagens de satélite LANDSAT TM5 e TM8 em escala 1:210.000 com o intuito de obter informações acerca dos elementos ambientais que compõem a bacia. Este método já foi amplamente utilizado em estudos com propósito igual ou semelhante ao deste estudo por PINHEIRO et al. (2011) e SANTOS et al. (2014).

As visitas in loco permitiram a observação direta da área de estudo para evidenciar as características relativas à vegetação, geologia e geomorfologia e a comparação dos resultados obtidos através das imagens de satélite e ocorreram nos meses de Fevereiro e Abril/2015. Nas visitas, foram efetuadas anotações escritas a partir de roteiros previamente elaborados com itens que identificaram a presença ou ausência dos aspectos relacionados à bacia (padrão do canal, tipo do leito, presença da mata ciliar, ocorrência de chuvas na data da coleta, tipos de moradia, presença/ausência de lançamento de efluentes, geologia e demais aspectos relevantes na rede de drenagem, como a presença de travertinos, formação de pontos de turbulência, presença de canais adjacentes, entre outros) e registros fotográficos. Ressalta-se que os aspectos relacionados ao tipo de solo e clima foram classificados apenas com base nos mapas temáticos e literaturas pertinentes ao tema respectivamente.

\section{Interpretação dos dados}

Os dados levantados através da análise dos mapas temáticos e observações in loco dos locais amostrados, foram organizados em relatórios descritivos. Posteriormente, foram interpretados e comparados gerando desta forma uma descrição integrada do local.

\section{RESULTADOS E DISCUSSÃO}

A bacia hidrográfica do córrego Jacobina possui área aproximada de $446 \mathrm{~km}^{2}$. Nasce nas serras e vales da Província Serrana, percorre trechos de depressão e deságua na margem esquerda do rio Paraguai. Os desníveis topográficos e os afloramentos rochosos principalmente de calcário e arenito no leito contribuem para formação de corredeiras e cachoeiras ao longo do perfil longitudinal, criando vários níveis de base local. 


\section{Clima}

No alto e médio cursos da bacia registra-se a ocorrência do Clima Tropical de Altitude Mesotérmico Quente da Fachada Meridional das Chapadas e Planaltos, definidos por TARIFA (2011). Segundo o autor, este tipo de clima ocorre nas cotas altimétricas que variam de 300 a 700 metros de altitude, conforme o alto curso da bacia do Jacobina.

Esta unidade climática foi subdividida em onze subunidades. A bacia do córrego Jacobina abrange a sub-unidade da Província Serrana em que o controle climático exerce maior importância nas cotas altimétricas de 300 a 700 metros, além das altas declividades e orientação de NNE-SSW. As áreas mais baixas (300-400 metros) são mais secas do que as cristas e as serras mais elevadas, logo, a pluviosidade anual varia de 1.400 a $1.600 \mathrm{~mm}$ com 4-5 meses de seca (junho/setembro-outubro) e um excedente hídrico de pequeno a moderado de outubro a abril (TARIFA, 2011).

Para TARIFA (2011), a declividade e o desnível altimétrico da Província Serrana são fatores que associados a variação da altitude e do clima, são importantes para compreender os processos pluviais que ocorrem nas bordas da Província Serrana e ainda sua influência na formação e flutuação do escoamento hídrico para as depressões.

No baixo curso da bacia ocorre o clima Tropical Megatérmico Subúmido das Depressões e Pantanais de Mato Grosso que foi subdivido em quatro subunidades, entre as quais se encontra a Depressão do Alto Paraguai nas cotas altimétricas de 100 a 200 metros, área em que se localiza a foz da bacia do córrego Jacobina sendo uma região bastante plana, característica de depressão e planície sazonalmente inundável, com aproximadamente 8 meses de deficiência hídrica (abril a novembro) e um excedente hídrico de janeiro a março (TARIFA, 2011).

\section{Vegetação}

No compartimento I, a vegetação apresenta-se da forma típica de cerrado com porções substituídas pela pastagem. Ocorrem as coberturas vegetais do tipo Savana Parque sem floresta de galeria, pecuária e predomínio da Savana Arborizada sem floresta de galeria (BRASIL, 1982) conforme Figura 2. Cabe salientar que a pecuária, demonstrada neste estudo, em virtude da pastagem, passa a ser considerada uma cobertura vegetal, no entanto, é verdadeiramente um tipo de uso do solo, não assumindo características fito fisionômicas, devido às atividades de criação de gado bovino predominante na região. 


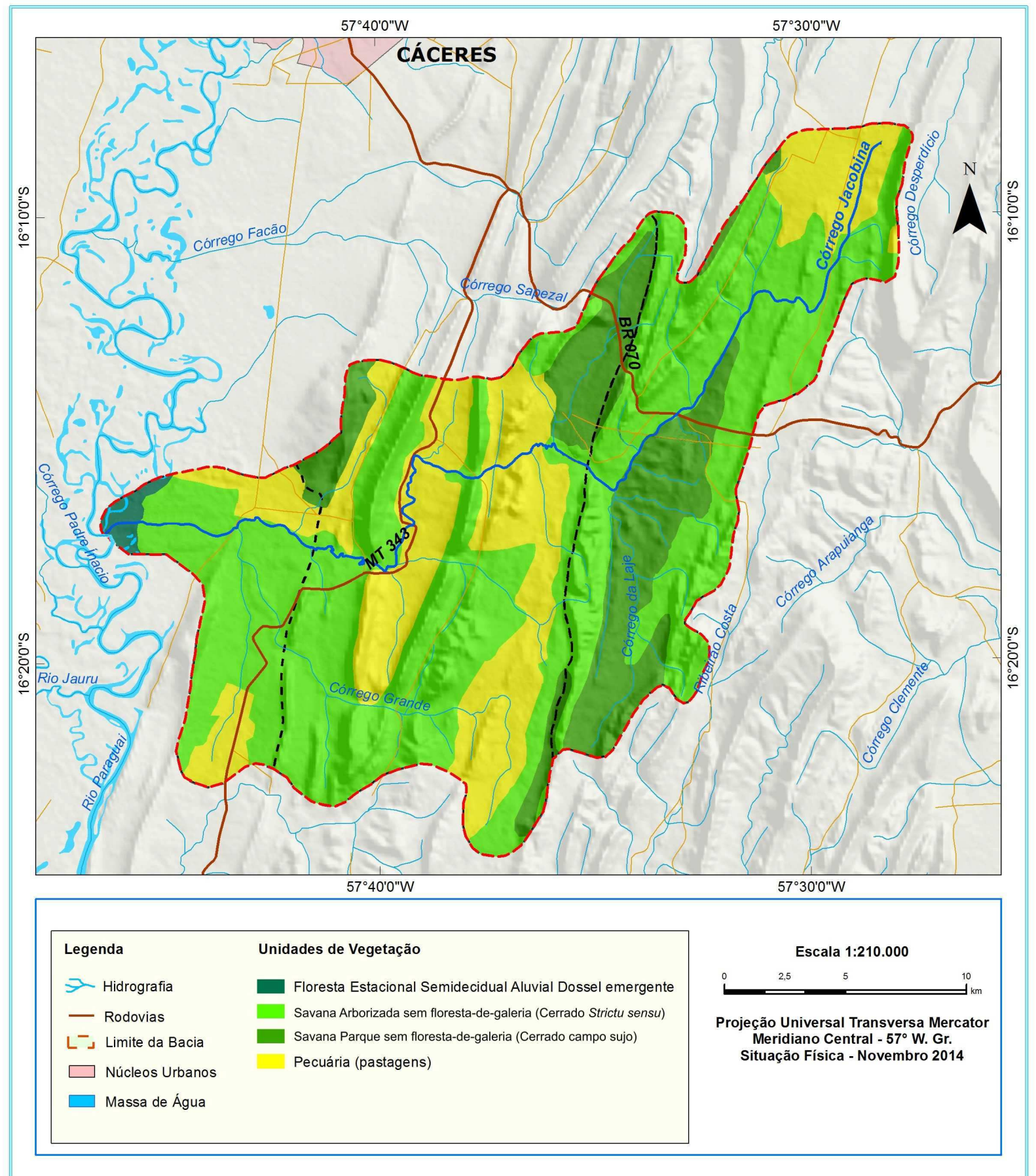

FIGURA 2. Unidades de vegetação da bacia hidrográfica do córrego Jacobina, Cáceres-MT.

Elaborado por: Gilmar de Souza Acácio.

Segundo as informações do mapa temático de unidades de vegetação, a Savana Arborizada sem floresta de galeria ocupa a maior área da bacia com $57,24 \%$. A pastagem ocupa $25,91 \%$ do total da área, a Savana Parque sem floresta de galeria ocupa $15,99 \%$ e a unidade Floresta Estacional Semidecidual Aluvial com Dossel emergente apenas $0,83 \%$ conforme a Tabela 1. 
TABELA 1. Área de abrangência das unidades de vegetação da bacia hidrográfica do córrego Jacobina, município de Cáceres-MT.

\begin{tabular}{lcc}
\hline Unidade de vegetação & Área $\left(\mathbf{K m}^{2}\right)$ & Área (\%) \\
\hline Floresta Semidecidual & 3,72 & 0,83 \\
Savana Parque & 71,37 & 15,99 \\
Pecuária & 115,66 & 25,91 \\
Savana Arborizada & 255,51 & 57,24 \\
Área total & 446,33 & 100 \\
\hline
\end{tabular}

Segundo IBGE (2012), o termo "Savana" é utilizado na literatura fitogeográfica por autores diferentes para designar essa vegetação e após levantamento das denominações utilizadas resolveu-se adotar o termo "Savana" como prioritário e "Cerrado" como sinônimo regionalista pela homologia com a fitofisionomia savânica.

Desta forma, as Savanas Arborizadas e as Savanas Parque constituem tipologias de cerrado diferindo pela densidade e estrato da vegetação, sendo a Savana Arborizada considerada com características de Cerrado Típico (Stricto Sensu) com árvores baixas, inclinadas e tortuosas e a Savana Parque com características de Cerrado Campo Sujo com aspecto herbáceo-arbustivo e arbustivo esparsos.

Neste segmento, é possível observar a presença de árvores de médio e grande porte, bastante espaçadas. O bacuri (Platonia insignis) foi frequentemente observado assim como pontos em que a cobertura do solo teve sua vegetação original substituída, ora para pastagem para o gado ora para prática da agricultura de soja e milho em grande extensão territorial.

No médio curso, a cobertura vegetal é composta por grande extensão de pastagem para o gado e no sentido jusante foram observadas as vegetações herbáceas e arbóreas de médio e grande porte principalmente na mata ciliar que apresenta-se bem preservada considerando a atividade de criação de gado e recreação que se desenvolve no local. Já no baixo curso, a vegetação compreende pequenas áreas de pastagens e próximo ao encontro com o rio Paraguai apresenta Floresta Estacional Semidecidual Aluvial Dossel Emergente. No entanto, o predomínio é de Savana Arborizada sem floresta de galeria (Figura 2).

O tipo de formação vegetal observado às margens do rio Paraguai, na foz do córrego Jacobina, a Floresta Estacional Semidecidual Aluvial Dossel Emergente, está relacionada com a mata ciliar, uma vez que o Código Florestal por meio da Lei $n^{\circ} 12651 / 12$ prevê limites diferentes de faixas cili ares de acordo com a largura do canal (BRASIL, 2012), logo, além de respeitar a largura do córrego, neste ponto especificamente, é preciso respeitar a largura do rio que oscila entre 80 e 120 metros aproximadamente de acordo com o período (estiagem e chuvoso).

Ademais, esta formação é típica de das depressões pantaneiras, pois caracteriza-se por uma formação florestal ribeirinha que ocupa as acumulações fluviais margeando os rios da bacia do rio Paraguai (PNMA,1997) e está condicionado à estacionalidade climática tropical, com épocas de intensas chuvas de verão seguidas de estiagens acentuadas (IBGE, 2012).

A mata ciliar encontra-se bastante preservada e apresenta-se com poucas árvores e muita vegetação arbustiva, com espécies de novateiro (Triplaris americana Linnaeus) nas margens que circundam a baía e macrófitas aquáticas formando vários bancos de aguapés: Eichhornia crassipes (Mart.) Solms. 


\section{Geologia}

$\mathrm{Na}$ bacia hidrográfica encontram-se vários tipos de formação geológica. A Formação Araras abrange a maior área de bacia, com $225,90 \mathrm{~km}^{2}$, representando $50,61 \%$ da área total. As outras formações compreendem entre 5,92\% com a Formação Sepotuba e 13,16\% com a Formação Raizama conforme o Projeto RADAMBRASIL (1982) observadas na Figura 3. A área de abrangência das unidades geológicas pode ser observada na Tabela 2 .

TABELA 2. Área e percentual de abrangência das unidades geológicas da bacia hidrográfica do córrego Jacobina, município de Cáceres-MT.

\begin{tabular}{lcc}
\hline \multicolumn{1}{c}{ Unidade geológica } & Área $\mathbf{( k m}^{\mathbf{2}} \mathbf{)}$ & Área (\%) \\
\hline Aluviões Holocênicos & 3,68 & 0,82 \\
Cobertura Detrítico-Laterítica & 57,02 & 12,78 \\
Formação Araras & 225,90 & 50,61 \\
Formação Moendas & 53,89 & 12,07 \\
Formação Raizama & 58,72 & 13,16 \\
Formação Sepotuba & 26,43 & 5,92 \\
Grupo Cuiabá & 20,69 & 4,64 \\
Total & $\mathbf{4 4 6 , 3 4}$ & $\mathbf{1 0 0 , 0 0}$ \\
\hline
\end{tabular}

No alto curso da bacia hidrográfica registra-se a ocorrência das seguintes formações geológicas: Raizama, Araras e Moendas e Grupo Cuiabá, com predominância das Formações Moendas e Araras (Figura 3) que são constituídas por rochas sedimentares.

Os afloramentos rochosos no sentido transversal do canal contribuem para o barramento natural do fluxo em vários trechos ao longo do perfil longitudinal, formando pequenas cachoeiras e corredeiras e de acordo com RITELA \& SOUZA (2008) constituem obstáculos que dificultam o escoamento da água, propiciando a formação de baciamentos e marmitas. Geralmente as marmitas aparecem após um desnível no leito e sua origem está associado a força da água e dos sedimentos transportados que provoca escavação.

O material particulado que entra no córrego tem sua fonte principalmente na geologia, tanto de forma física (calcita, silte, argila, areia, fragmentos de rochas, etc) quanto de forma química, considerando a composição das rochas, especialmente o calcário calcítico e dolomítico, que libera íons em solução aquosa, pois segundo ALBERÈDE (2011), os íons de cálcio e magnésio são provenientes de calcários calcíticos e dolomíticos frequentemente observados através de afloramentos rochosos nesta seção.

A estruturação da Formação Araras é constituída por rochas carbonáticas, sendo caracterizada na porção inferior e meias encostas, essencialmente por calcários pelíticos e calcíticos. O calcário dolomítico ocorre com maior abundância, apresentando feições topográficas típicas desta formação (BARROS et al., 1982).

A calcita é um mineral originário da dissolução e precipitação das rochas carbonáticas e a sua dissolução na água, libera cálcio e carbonatos (ALBERÈDE, 2011), elementos químicos que podem estar associados às variáveis que caracterizam o estado da água, como $\mathrm{pH}$, dureza, condutividade elétrica, entre outros. 
Litologicamente a Formação Raizama apresenta em sua base frequentes intercalações de camadas de arenitos grosseiros e conglomerados com matriz arenosa fina, média e grossa. É constituído por cores claras, com tonalidades esbranquiçadas, bege, cinza-claro, rósea e mais raramente arroxeada, camadas conglomeráticas com seixos de quartzo atingindo até $3 \mathrm{~cm}$ (BARROS et al., 1982). A Formação Moenda, antes denominada Formação Puga tem seu posicionamento litoestratigráfico na Formação Araras, pois está subjacente aos calcários calcíticos desta formação (BRASIL, 1982).

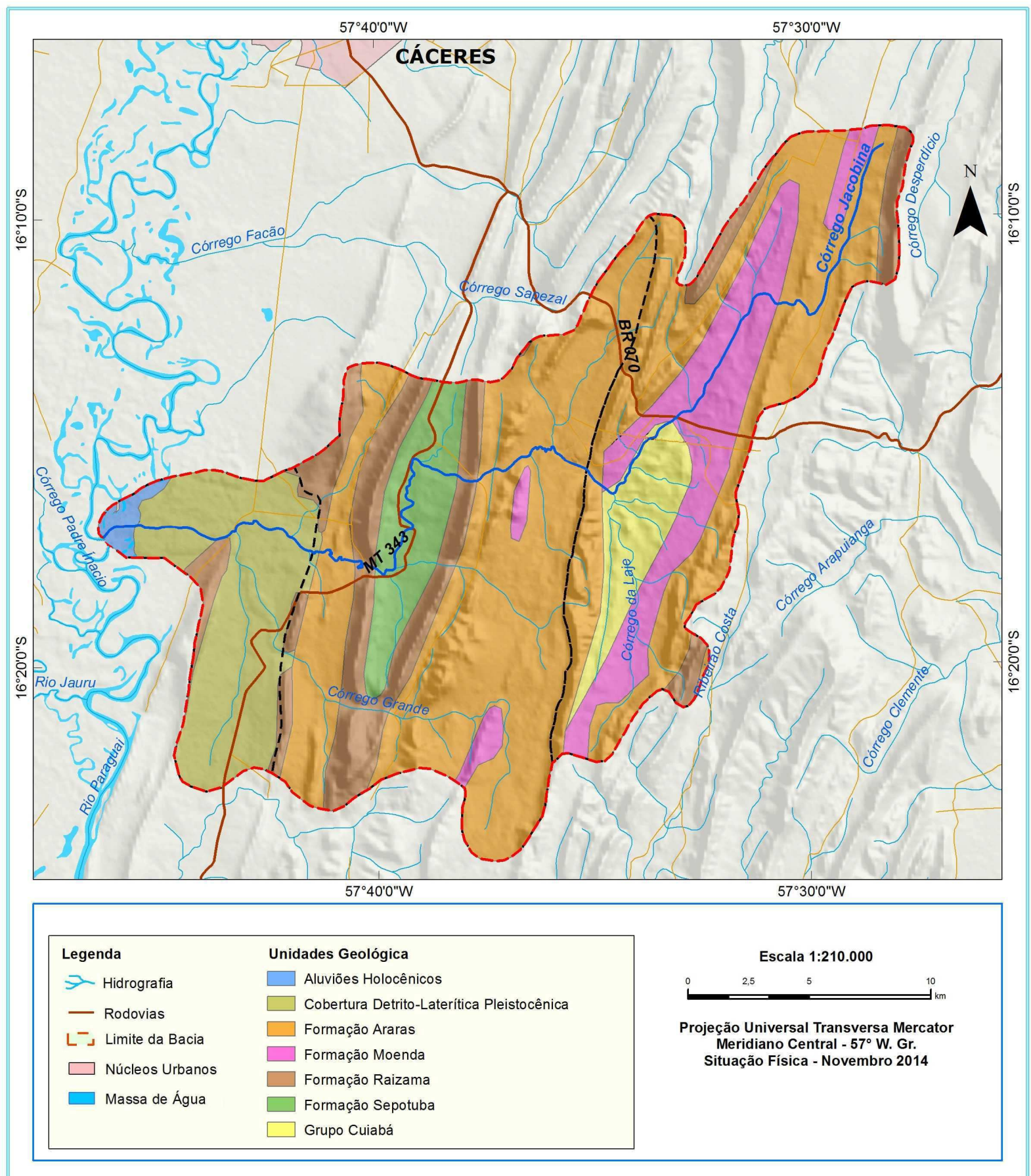

FIGURA 3. Unidades geológicas da bacia hidrográfica do córrego Jacobina, Cáceres-MT.

Elaborado por: Gilmar de Souza Acácio.

ENCICLOPÉDIA BIOSFERA, Centro Científico Conhecer - Goiânia, v.13 n.23; p.1560 
No médio curso, entre as unidades geológicas, estão presentes as Formações Araras, Sepotuba, Moendas, Raizama e um pequeno trecho de material pertencente ao Grupo Cuiabá (Figura 3). De acordo com Projeto RADAMBRASIL (1982), a Formação Sepotuba é composta de argilitos, folhelhos e siltitos, ocupando os flancos mais externos das anticlinais e as estruturas dobradas em sinclinais. $O$ Grupo Cuiabá apresenta diversas litologias como xistos, filitos, metagravaucas, metarenitos, metacórseos, ardósias, metassiltitos, mármores e metaparaconglomerados que apresentam-se compondo parte da unidade da Depressão do Paraguai. As formas de relevo desses tipos de rochas apresentam o topo plano em cotas altimétricas aproximadas a 200 a 250 metros (BRASIL, 1982).

Observou-se neste compartimento, muitos afloramentos rochosos de calcário, tanto calcíto quanto o dolomítico e arenitos. Este material está sujeito às ações do tempo (intemperismos) que o carregam para o canal de maneira que se depositam no fundo, deixando o leito rochoso.

Geologicamente, são encontradas no baixo curso a formação Raizama, além de uma faixa predominante de cobertura detrítico-laterítico pleistoscênica e aluviões holocênicos. Os aluviões atuais encontrados na foz (Figura 3) são compostos por areias quartzosas de granulação fina e fina a média, siltes, argilas e cascalhos relativos aos depósitos de planície de inundações fluviais e fluviolacustres de idade Holocênica. Apresentam estratificação gradacional, com granulometria decrescente da base para o topo e intercalações e interdigitações de camadas de areias e siltes. Eventualmente ocorrem depósitos de barra em pontal exibindo estratificação cruzada e pelitos finamente laminados (ANJOS \& OKIDA, 2000).

\section{Geomorfologia}

O canal fluvial apresenta-se com padrão meandrante encaixado em vale, com as margens bem definidas, com presença de afloramentos no leito e nas margens em alguns trechos. Segundo SILVA et al. (2008), os padrões de canal podem ser definidos pelas características morfológicas e dinâmicas do segmento fluvial e tais características incluem o tipo de canal, a composição da margens, a razão entre a largura e profundidade, velocidade do fluxo, carga de sedimentos entre outros.

O alto curso da bacia hidrográfica do córrego Jacobina encontra-se nas serras e vales da Província Serrana (Dobramentos Antigos do Alto Paraguai) que define-se como um conjunto de serras paralelas entre si, com relevo entalhado em uma estrutura dobrada na Formação do Alto Paraguai. Comportando truncamentos de topo e moldadas em rochas duras (Formação Raizama), com sinclinais suspensas e anticlinais escavadas (vales abertos em rochas tenras) (ROSS \& SANTOS, 1982). As serras que compõem o alto curso são as Serras da Jacobina, da Campina e Linda.

O conjunto de vales e serras da Província Serrana que atuam no compartimento I, através do relevo influenciam a morfologia e o padrão de drenagem do canal, observados pela presença de travertinos, afloramentos rochosos e meandros encaixados. No médio curso, o leito do canal fluvial é bastante rochoso, em parte por rochas que naturalmente compõem a geologia da bacia e em parte devido ao material que se desprende dos afloramentos rochosos encontrados a montante, no alto curso. Neste compartimento o canal fluvial apresenta-se mais largo e mais profundo do que o compartimento I, porém, ainda com muitos afloramentos rochosos e presença de travertinos. Isto indica que nesta seção, o canal sofre influências do material litológico proveniente do calcário. Além do 
calcário, também sofre influência do material arenítico oriundo principalmente da Formação Raizama evidenciada no mapa temático de unidades geológicas (Figura 3).

O baixo curso está inserido na unidade geomorfológica Depressão do rio Paraguai. Esta depressão compreende superfícies aplanadas, recobertas por sedimentos recentes em que por vezes podem ocorrer formas dissecadas de topo plano, convexas e aguçadas (BRASIL, 1982).

Especialmente neste compartimento, a área abrange o pantanal matogrossense que funcionam como planícies de acumulação de sedimentos, topograficamente plana e com alagamentos periódicos (SOUZA \& SOUSA, 2010) conforme observou-se na foz do córrego Jacobina.

Neste compartimento, é possível observar duas características do canal. No trecho que liga as propriedades rurais, o canal possui leito rochoso, provavelmente associado ao material trazido pelos compartimentos à montante. Já na foz, onde as águas do córrego encontram-se com as águas do rio, o leito é arenoso, pois sofre influência dos materiais trazidos pelas águas do rio Paraguai proveniente da navegação e das diversas atividades de uso da terra, das pousadas e outras propriedades localizadas às margens, como a substituição da vegetação natural por pastagem, dessedentação de animais no barranco, entre outras. O material arenoso que se deposita no fundo também pode estar relacionado com a formação geológica do tipo Raizama que ocorre neste segmento.

O ponto em que a água do córrego deságua no rio Paraguai forma uma baía de águas calmas circundada pela vegetação ciliar. Isso dificulta a remoção e o transporte de sedimentos que se depositam no fundo do canal. Desta forma, ao longo do tempo é possível que o processo de sedimentação seja mais expressivo e exerça influência nos processos de inundação da planície.

\section{Solo}

Os solos constituem uma coleção de corpos naturais de partes sólidas, líquidas e gasosas, tridimensionais, dinâmicos, formados por materiais minerais e orgânicos que ocupam a maior parte do manto superficial das extensões continentais do planeta. Contém matéria viva, podem ser vegetados na natureza onde ocorrem e podem, eventualmente, sofrer modificações por interferências antrópicas (EMBRAPA, 2006).

No entanto, as características mineralógicas e químicas dos solos são, em grande parte, ditadas pela natureza do material de origem e do regime de inundações periódicas, conferindo aos solos características diferenciadas, como alta saturação de sódio e, em alguns casos, de alumínio, textura variável em decorrência do tipo de sedimento depositado e riqueza em argilas expansivas (FERNANDES et al., 2007).

As classes de solos encontradas na bacia foram Gleissolo Háplico Ta Eutrófico, Latossolo Vermelho Disrófico, Argissolo Vermelho-Amarelo Distrófico, Argissolo Vernelho-Amarelo Eutrófico, Argissolo Vermelho Eutrófico, Neossolo Litólico Distrófico, Neossolo Litólico Eutrófico e Vertissolo Hidromórfico Órtico. Suas áreas de abrangência estão apresentadas na Tabela 3. 
TABELA 3. Área de abrangência do tipo de solo da bacia do córrego Jacobina, município de Cáceres-MT.

\begin{tabular}{lcc}
\hline Tipo de solo & Área $\left(\mathbf{K m}^{2}\right)$ & Área $(\%)$ \\
\hline Gleissolo Háplico Ta Eutrófico & 3,68 & 0,82 \\
Latossolo Vermelho Distrófico & 1,56 & 0,34 \\
Argissolo Vermelho-Amarelo Distrófico & 92,29 & 20,66 \\
Argissolo Vermelho-Amarelo Eutrófico & 29,93 & 6,70 \\
Argissolo Vermelho Eutrófico & 163,41 & 36,60 \\
Neossolo Litólico Distrófico & 88,58 & 19,84 \\
Neossolo Litólico Eutrófico & 65,01 & 14,55 \\
Vertissolo Hidromórfico Órtico & 2,19 & 0,49 \\
Total & $\mathbf{4 4 6 , 3 4}$ & $\mathbf{1 0 0}$ \\
\hline
\end{tabular}

Os tipos de solo encontrados no alto curso foram o Vertissolo Hidromórfico Órtico, Neossolo Litólico Eutrófico e Distrófico, com predominância do Argissolo Vermelho Eutrófico (Figura 4). Os Argissolos são solos constituídos por material mineral com argila de atividade baixa ou com argila de atividade alta conjugada com saturação por bases baixa; Acrescenta-se que quando ele é Vermelho Eutrófico a saturação por bases é maior e/ou igual a 50\% (EMBRAPA, 2006).

Os Neossolos são solos pouco evoluídos, constituídos por material mineral ou por material orgânico com menos de $20 \mathrm{~cm}$ de espessura. São litólicos, quando apresentam $90 \%$ ou mais da sua massa constituída por fragmentos de rocha com diâmetro de 2 mm (cascalhos, calhaus e matacões) (EMBRAPA, 2006). Ao analisar a influência dos fatores geológicos e hidrogeológicos na estabilidade química das águas freáticas no sul do estado do Tocantins, AZEVEDO et al. (2014) também encontrou Neossolos Litólicos na região em que associou o desenvolvimento do solo ao intemperismo de granitos e gnaisses em partes mais elevadas do terreno.

Os Vertissolos são solos constituídos por material mineral com horizonte vértico entre 25 e $100 \mathrm{~cm}$ de profundidade. Quando são hidromórficos têm o horizonte glei dentro dos primeiros $50 \mathrm{~cm}$, ou entre 50 e $100 \mathrm{~cm}$ desde que precedido por horizonte de cores acinzentadas (EMBRAPA, 2006).

No médio curso, registram-se os solos do tipo Neossolo Litólico Distrófico, Neossolo Litólico Eutrófico, Argissolo Vermelho Eutrófico e Argissolo Vermelho Amarelo Eutrófico (Figura 4), com predomínio do segundo e terceiro tipos.

Os solos Neossolo Litólico Distrófico e Argissolo Vermelho Amarelo Eutrófico foram também encontrados na bacia do Aguapeí em áreas de serra para o primeiro tipo e depressão, planície e planalto para o segundo tipo, por RITELA \& SOUZA (2008). De maneira geral, os neossolos litólicos e os argissolos vermelho-amarelo, ocorrentes neste compartimento, são classes de solo com alta erodibilidade (NEVES, et al. 2011), desta forma, é possível relacionar os efeitos do uso da terra neste segmento com a fragilidade dos solos apresentados.

Destaca-se que o material proveniente desses solos (areia e argila) são facilmente carreados para o canal e tendem a permanecer no fundo (a areia) e em suspensão (a argila), dependendo da velocidade do fluxo das águas e do quanto a turbulência conseguir mantê-los desta forma. No baixo curso o hidromorfismo, favorecido pelo relevo plano, que por sua vez explica a tendência às inundações periódicas, exerce influência sobre os solos (SOUSA \& SOUZA, 2013). Assim, os solos do baixo curso Gleissolo Háplico Ta Eutrófico, Argissolo Vermelho-Amarelo Distrófico, Argissolo Vermelho Eutrófico e Neossolo Litólico Distrófico, com 
predomínio de Argissolo Vermelho-Amarelo Distrófico (Figura 4), são influenciados pelas suas condições de relevo.

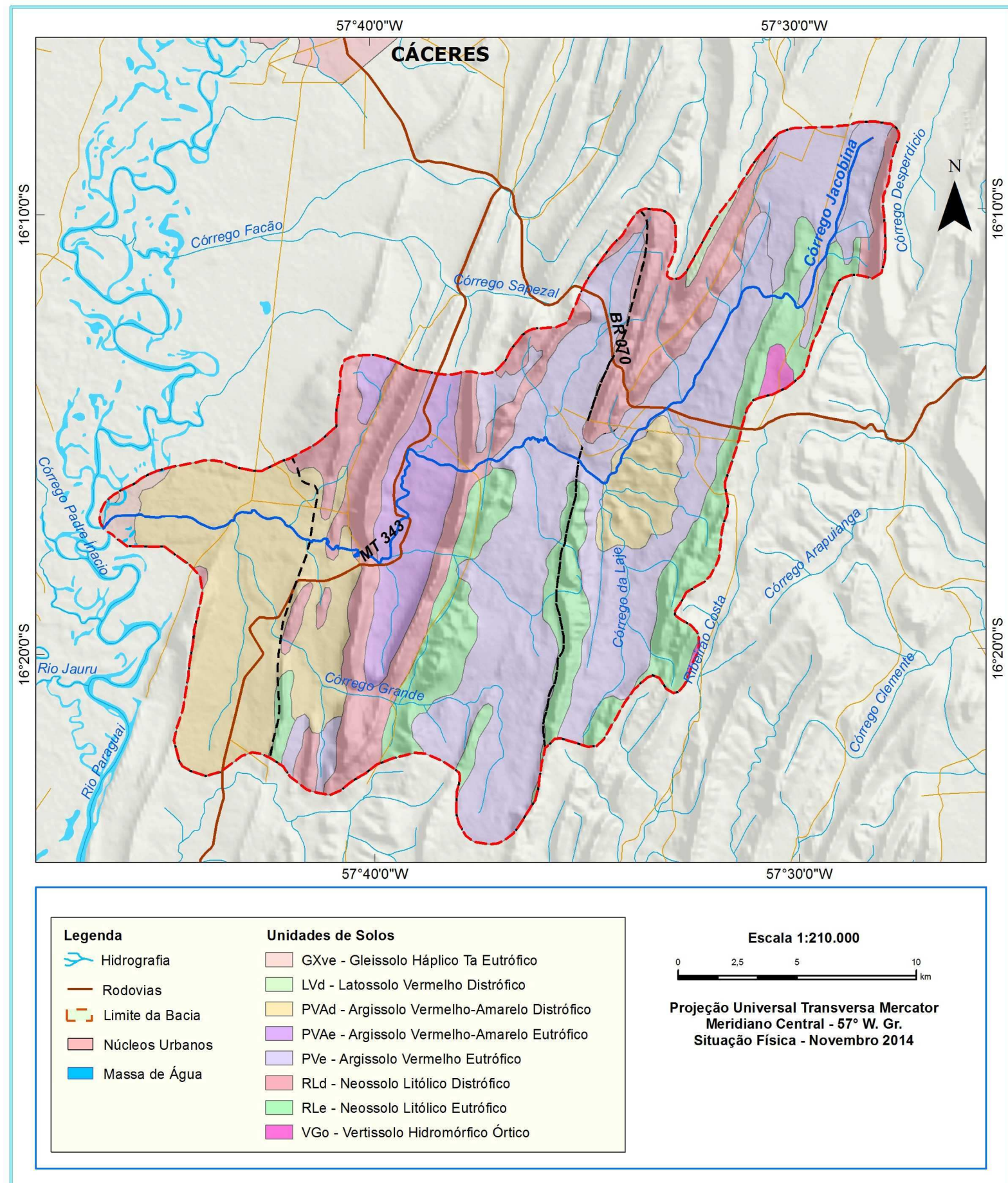

FIGURA 4. Unidades de solo da bacia hidrográfica do córrego Jacobina, CáceresMT.

Elaborado por: Gilmar de Souza Acácio.

Os Gleissolos são solos constituídos por material mineral com horizonte glei iniciando-se dentro de $150 \mathrm{~cm}$ da superfície e quando são das subordens Háplico Ta Eutrófico, possuem argila de atividade alta e baixa saturação por bases nos primeiros $100 \mathrm{~cm}$ a partir da superfície do solo (EMBRAPA, 2006). É 
reconhecidamente, o tipo de solo encontrado em barrancos e margens de cursos d'água pela sua capacidade de encharcar.

Esta característica especificamente demonstra a fragilidade do solo quanto ao uso para plantio e, portanto merecem destaque quanto à sua preservação. Desta forma, as áreas de preservação permanente já protegidas pelo Código Florestal Brasileiro (2012) seriam efetivamente respeitadas.

Este tipo de solo, também foi encontrado por CORINGA et al. (2012), ao estudar os atributos de solos hidromórficos no Pantanal norte mato-grossense, avaliando suas características químicas em relação ao ambiente no qual foram formados. A classe Gleissolo Háplico também foi encontrada por SOUSA \& SOUZA (2013) em estudo sobre caracterização morfológica e mineralógica de solos em ambientes de cordilheira e campo de inundação no Pantanal de Poconé, Mato Grosso.

Os elementos ambientais que caracterizam a bacia hidrográfica se interrelacionam de maneira a explicar a estrutura e funcionamento do córrego Jacobina. Assim, o levantamento dos aspectos relacionados à vegetação, clima, solo, geologia e geomorfologia puderam contribuir para a formação de um diagnóstico ambiental que poderá subsidiar medidas de gestão ambiental sustentáveis para a bacia.

As características levantadas sobre a bacia sugerem que a área possui grande potencial de uso da terra e conservação da biodiversidade ao mesmo tempo. Ressalta-se, portanto, a relevância que as atividades de agricultura e criação de animais que podem ser desenvolvidas no entorno, exercem sobre a comunidade local, bem como para todo o município de Cáceres, pois desta forma, a oferta de produtos oriundos da própria região, valorizam não somente os pequenos proprietários das terras, mas também a sustentabilidade ambiental.

\section{CONCLUSÕES}

A formação geológica predominante é a Formação Araras, presente no alto e médio curso da bacia, em que as rochas são de origem sedimentar e constituídas especialmente de carbonatos. Os afloramentos rochosos formam marmitas que constituem barreiras para o escoamento superficial e formam pontos de acúmulo de água no entorno do córrego.

Dentro do canal, os travertinos são responsáveis pela formação de pontos de turbulência da água que removem sedimentos de fundo, misturando-os com os sedimentos suspensos quando levados pela correnteza, influenciando aspectos físicos da água, como a transparência.

A vegetação predominante na bacia são formações influenciadas pelas estações climáticas e típicas de vegetação ripária, como ocorrem no Pantanal e predominância de fitofisionomias de cerrado especialmente no alto e médio cursos da bacia.

A classificação dos solos indicou que os tipos de solo de maior ocorrência são - Argissolo Vermelho Eutrófico no alto e médio curso e o Argissolo VermelhoAmarelo Distrófico no baixo curso e permitiu estabelecer relações com as fragilidades apresentadas em ambientes suscetíveis à erosão, no entanto, análises físicas do solo precisam ser realizadas no sentido de comprovar as informações dos mapas temáticos, além de quantificar o material predominante dos solos. 


\section{REFERÊNCIAS}

ALBARÈDE, F. Geoquímica: Uma introdução. São Paulo: Oficina de Textos, 2011, 400p.

ANJOS, C. E.; OKIDA, R. Geologia. In: Zoneamento Ambiental da Borda Oeste do Pantanal: maciço do Urucum e adjacências. João dos Santos Vila da Silva (Org). Brasília: Embrapa Comunicação para Transferências de Tecnologia, 2000. 211 p.

AZEVEDO, J. H.; CAMPOS, J. E. G.; BOAVENTURA, G. R. Influência dos fatores geológicos e hidrogeológicos na estabilidade química das águas freáticas no sul do estado do Tocantins. São Paulo, UNESP, Geociências, v. 33, n. 1, p. 73-88, 2014.

BARROS, A. M.; SILVA, R. H.; CARDOSO, O. R. F. A.; FREIRE, F. A.; SOUZA JUNIOR, J. J.; RIVETTI, M.; LUZ, D. S.; PALMEIRA, R. C. B.; TASSINARI, C. C. G. Geologia. In: Projeto RADAMBRASIL. Folha SD. 21 - Cuiabá: Geologia, Geomorfologia, Pedologia, Vegetação e Uso potencial da terra. Rio de Janeiro, 1982. p. $25-192$.

BRASIL. Ministério das Minas e Energia. Projeto RADAMBRASIL. Folha SD. 21 Cuiabá: Geologia, Geomorfologia, Pedologia, Vegetação e Uso potencial da terra. Secretaria Geral. Rio de Janeiro, 1982. 544 p.

BRASIL. Ministério do Meio Ambiente. Lei no 12.651, de 25 de Maio de 2012. Dispõe sobre a proteção da vegetação nativa; altera as Leis nํㅗ 6.938 , de 31 de agosto de 1981, 9.393, de 19 de dezembro de 1996, e 11.428, de 22 de dezembro de 2006; revoga as Leis nos 4.771 , de 15 de setembro de 1965, e 7.754, de 14 de abril de 1989, e a Medida Provisória oㅡ 2.166-67, de 24 de agosto de 2001; e dá outras providências. Diário Oficial União, Brasília, DF (maio/2012).

CONCEIÇÃO, J. A.; OLIVEIRA, A. C. S.; SILVA, C. C.; LISBOA, V. A. C.; ROSA, M. L. S.; CONCEÇÃO, H. Caracterização geológica, petrográfica e geoquímica do Maciço Granítico Glória Sul, domínio Macururé, faixa de dobramentos sergipana. Cadernos de Geociências, v. 9, n. 1, maio 2012.

CORINGA, E. A. O.; COUTO, E. G.; PEREZ, X. L. O.; TORRADO, P. V. Atributos de solos hidromórficos no Pantanal Norte Matogrossense. Acta Amazônica, vol. 42, n.1, p. $19 \quad-\quad 28, \quad 2012$ :. Disponível em: < http://dx.doi.org/10.1590/S004459672012000100003 >. DOI: $10.1590 / S 004459672012000100003$

EMBRAPA - Empresa Brasileira de Pesquisa Agropecuária. Sistema Brasileiro de Classificação dos Solos. Rio de Janeiro: Embrapa, 2 ed. 2006.

FERNANDES, F. A.; FERNANDES, A. H. B. M.; SOARES, M. T. S.; PELLEGRIN, L. A.; LIMA, I. B. T. 2007. Update Map of Soils of the Pantanal lowlands for the Brazilian System of Soil Classification. Comunicado Técnico 61 - Brasília-DF: Embrapa Pantanal, Corumbá-MS, 6 p. 
GUERRA, A. T.; GUERRA, A. J. T. Novo dicionário geológico-geomorfológico. $6^{\underline{a}}$ ed. Rio de Janeiro: Bertrand Brasil, 2008.

IBGE - Instituto Brasileiro de Geografia e Estatística. Manual Técnico da Vegetação Brasileira. Rio de Janeiro, 271p., 2012.

LIMA, W. P.; ZAKIA, M. J. B. Hidrologia de matas ciliares. In: RODRIGUES, R. R.; LEITÃO-FILHO, H. F. (Ed.). Matas Ciliares: conservação e recuperação. São Paulo: Edusp, Fapesp, $2^{\mathrm{a}}$ ed, 2004. 320p.

MACEDO, H. A.; ASSINE, M. L.; SILVA, A.; PUPIM, F. N.; MERINO, E. R.; STEVAUX, J. C. Mudanças paleo-hidrológicas na planície do rio Paraguai, quaternário do pantanal. Revista Brasileira de Geomorfologia, São Paulo, v. 15, n. 1, p. 75-85, 2014. Disponível em: < http://lsie.unb.br/rbg/index.php?journal=rbg\&page=article\&op=view\&path[]=431> DOI: http://dx.doi.org/10.20502/rbg.v15i1.431

MARTINS, F. P.; COSTA, R. A. A compartimentação do relevo como subsídio aos estudos ambientais no município de Ituiutaba-MG. Revista Sociedade \& Natureza, Uberlândia, v. 26, n.2, p. 317-331, 2014. Disponível em: < http://www.seer.ufu.br/index.php/sociedadenatureza/article/view/21735/pdf 88> DOI: 10.1590/1982-451320140209.

NEVES, S. M. A. S.; MOTINHO, M. C.; NEVES, R. J.; SOARES, E. R. C. Estimativa de perda de solo por erosão hídrica na bacia hidrográfica do rio Jauru-MT. Revista Sociedade \& Natureza. Uberlândia, v. 23, n. 3, p. 423-434, set/dez. 2011. Disponível em: < http://dx.doi.org/10.1590/S1982-45132011000300005 > DOI: $10.1590 /$ S1982-45132011000300005

PINHEIRO, A.; BERTOLDI, J.; VIBRAN, A. C.; KAUFMANN, V.; DESHAVES, M. Uso do solo na zona ripária de bacias agrícolas de pequeno a médio porte. Revista Árvore, Viçosa-MG, v.35, n.6, p.1245-1251, 2011. Disponível em: < http://dx.doi.org/10.1590/S0100-67622011000700011 > DOI: 10.1590/S010067622011000700011.

PNMA - Programa Nacional do Meio Ambiente. Plano de Conservação da Bacia do Alto Paraguai - PCBAP/Projeto Pantanal. Vol. II, Tomo III, Brasília: 1997.

RITELA, A.; SOUZA, C. A. Caracterização da bacia hidrográfica do rio Aguapeí-MT, como subsídio para uso e conservação. Revista eletrônica da associação dos geógrafos brasileiros - Seção Três Lagoas, Três Lagoas-MS, nº7, ano 5, 2008.

ROSS, J. L. S. Geografia do Brasil. Ed. Didática, São Paulo, 2011.

ROSS, J. L. S.; SANTOS, L. M. Geomorfologia. In: BRASIL. Ministério das Minas e Energia. Secretaria Geral. Projeto RADAMBRASIL. Folha SD. 21 - Cuiabá: Geologia, Geomorfologia, Pedologia, Vegetação e Uso potencial da terra. Rio de Janeiro, 1982. p. 193 - 256. 
SALAMENE, S.; FRANCELINO, M. R.; VALCARCEL, R.; LANI, J. R; SÁ, M. M. F. Estratificação e caracterização ambiental da área de preservação permanente do rio Guandu/RJ. Revista Árvore, Viçosa-MG, v.35, n.2, p.221-231, 2011. Disponível em: <http://dx.doi.org/10.1590/S0100-67622011000200007> DOI: 10.1590/S010067622011000200007

SANTOS, L. T. S. O.; JESUS, T. B.; NOLASCO, M. C. Influência do uso e ocupação do solo na qualidade das águas superficiais do rio Subaé, Bahia. Geographia Opportuno Tempore, Londrina, v. 1, n. 1, p. 68-79, jan./jun. 2014.

SILVA, A.; FILHO, E. E. S.; CUNHA, S. B. Padrões de canal do rio Paraguai na região de Cáceres (MT). Revista Brasileira de Geociências, v.38, n.1, 2008.

SOUSA, J. B.; SOUZA, C. A. de. Caracterização morfológica e mineralógica de solos em ambientes de cordilheira e campo de inundação no pantanal de Poconé, Mato Grosso. Boletim de Geografia. Maringá, v. 31, n. 1, p. 53-66, jan.-abr., 2013. Disponível em: <http://www.periodicos.uem.br/ojs/index.php/BolGeogr/article/view/17506/10244> DOI: 10.4025 .

SOUZA, C. A.; CUNHA, S. B. Feições morfológicas do rio Paraguai e sua dinâmica entre a cidade de Cáceres e a Estação Ecológica da llha de Taiamã-MT. In: SOUZA, C. A. (Org.). Bacia hidrográfica do rio Paraguai - MT: dinâmica das águas, uso, ocupação e degradação ambiental. São Carlos-SP: ed. Cubo, 2012. p. 81 - 94.

SOUZA, C. A.; SOUSA, J. B. Pantanal mato-grossense: origem, evolução e as características atuais. Revista Eletrônica da Associação dos Geógrafos Brasileiros - Seção Três Lagoas/MS, № 11, Ano 7, 2010.

TARIFA, J. R. Clima: análise e representação cartográfica. In: Mato Grosso Secretaria de Estado de Planejamento e Coordenação Geral. Recursos naturais e estudos ambientais. Cuiabá-MT: Entrelinhas, 2011. 102 p.

TEIXEIRA, W.; FAIRCHILD, T. R.; TOLEDO, M. C. M.; TAIOLI, F. Decifrando a Terra. Editora Nacional, São Paulo, 2009.

TORRES, F. T. P.; NETO, R. M.; MENEZES, S. O. Introdução à Geomorfologia. São Paulo: Cengage Learning, 2012.

TUCCI, C. E. M.; MENDES, C. A. Avaliação ambiental integrada de bacia hidrográfica / Ministério do Meio Ambiente / SQA. - Brasília: MMA, 2006. 